\title{
Aspectos morfométricos da cicatrização do cólon descendente de eqüinos submetidos a enterorrafias aposicionais com poliglactina 910 e com cianoacrilato
}

\author{
[Morphometric aspects of the healing of descending colon of horses submitted to appositional suture \\ techniques with polyglactin 910 and with cyanoacrilate] \\ C.A. Duarte ${ }^{1}$, J.W. Cattelan ${ }^{2 *}$, F.A. Lucas $^{3}$, G.S. Godoy ${ }^{4}$ E.B. Malheiros ${ }^{2}$ \\ D. Oliveira ${ }^{4}$, S.M. Baraldi-Artoni ${ }^{2}$ \\ ${ }^{1}$ Centro Universitário Barão de Mauá - Ribeirão Preto, SP \\ ${ }^{2}$ Faculdade de Ciências Agrárias e Veterinárias - UNESP \\ Via de Acesso Prof. Paulo Donato Castellane, s/n \\ 14884-900 - Jaboticabal, SP \\ ${ }^{3}$ Centro Universitário Moura Lacerda - Ribeirão Preto, SP \\ ${ }^{4}$ Aluno de pós-graduação - FCAV - UNESP - Jaboticabal, SP
}

\begin{abstract}
RESUMO
Foi realizado estudo morfométrico do cólon descendente de 15 eqüinos hígidos, nove fêmeas e seis machos, submetidos a enterorrafias aposicionais com fio de poliglactina 910 ou com cianoacrilato. Os animais foram distribuídos aleatoriamente em cinco grupos de três animais cada e sacrificados aos três, sete, 14, 35 e 70 dias de pós-operatório para colheita dos segmentos intestinais operados e posterior processamento histológico de rotina. A análise morfométrica foi feita em microscópio óptico adaptado a um sistema de análise de imagens, onde se quantificou o infiltrado inflamatório, mediante contagens de neutrófilos, eosinófilos, macrófagos, linfócitos e plasmócitos, não sendo observadas diferenças $(\mathrm{P}>0,05)$ entre as enterorrafias. Houve diferenças significativas entre os dias de pós-operatório para as contagens de neutrófilos, eosinófilos, macrófagos e linfócitos. Também se mensuraram as espessuras das regiões operadas (cicatriz) e das áreas contíguas não operadas (controle), registrando-se diferenças entre os dias de pós-operatório e as regiões $(\mathrm{P} \leq 0,05)$, mas não entre as enterorrafias. $\mathrm{O}$ fio de poliglactina 910 e o cianoacrilato apresentam a mesma eficácia para serem usados em enterorrafias aposicionais do cólon descendente de eqüinos.
\end{abstract}

Palavras-chave: eqüino, poliglactina, cianoacrilato, cólon descendente, enterorrafia, morfometria

\begin{abstract}
A morphometric study was carried out in descending colon of 15 healthy horses, nine females and six males, submitted to appositional suture techniques with polyglactin 910 or with cyanoacrilate. The animals were randomly distributed in five groups of three animals each and sacrificed on postoperative days 3, 7, 14, 35 or 70 in order to collect the operated intestinal segments. The morphometric evaluation was done with an optic microscope adapted to an image analysis system, where was counted the inflammatory infiltrated, through neutrophils, eosinophils, macrophages, lymphocytes and plasmacytes counting. No difference (P>0.05) was observed between the two suture techniques. There were significant differences between postoperative days related to the counting of neutrophils, eosinophils, macrophages and lymphocytes. It was also measured the thickness of operated regions (scar) and non operated nearby areas (control); it registered differences between the postoperative days and the regions $(P \leq 0.05)$, but not between the sutures. The polyglactin 910 and the cyanoacrilate showed the same efficacy to be used in appositional enterorrhaphies in equine descending colon.
\end{abstract}

Keywords: equine, polyglactin, cyanoacrilate, descending colon, enterorrhaphy, morphometry

Recebido em 9 de setembro de 2005

Aceito em 25 de setembro de 2006

*Autor para correspondência (corresponding author)

E-mail: cattelan@fcav.unesp.br 


\section{INTRODUÇÃO}

O tratamento cirúrgico das afecções do cólon descendente de eqüinos pode ser feito mediante a enterotomia ou ressecção e anastomose (Stashak, 1982; Beard et al., 1989). A enterorrafia desse segmento intestinal pode ser realizada com suturas aposicionais como a interrompida simples perfurante total (Lucas et al., 2001; Duarte et al., 2002), crushing e Gambee (Stashak, 1982), cujas vantagens são o bom alinhamento dos planos intestinais, pequeno comprometimento vascular e diâmetro luminal inalterado (Stashak, 1982).

Os materiais de sutura mais empregados no cólon descendente de eqüinos são os fios absorvíveis sintéticos, havendo várias pesquisas com a poliglactina 910 (Beard et al., 1989; Edwards, 1997; Lucas et al., 2001; Duarte et al., 2002), contudo, há poucos estudos com adesivos como o cianoacrilato (Duarte et al., 2002).

As alterações histológicas da parede intestinal podem ser verificadas pela morfometria, especialmente as lesões de isquemia e reperfusão (Faleiros et al., 2001) e enterotomia (Lucas, 2003). Lucas (2003) quantificou a reação inflamatória no cólon descendente de eqüinos submetidos a duas técnicas de sutura com fio de poliglactina 910, uma aposicional e outra invaginante, concluindo que este método de avaliação é adequado para mensurar e comparar a reação inflamatória resultante.

A escassez de estudos com adesivos à base de cianoacrilato no trato intestinal de eqüinos e a pequena quantidade de informações a respeito da cicatrização do cólon descendente desta espécie estimulam investigações adicionais sobre o assunto. Assim, o objetivo desta pesquisa foi complementar o estudo de Duarte et al. (2002), mediante a quantificação do infiltrado inflamatório e a mensuração da cicatriz obtida no cólon descendente de eqüinos submetidos a enterorrafias aposicionais com poliglactina $910 \mathrm{e}$ com adesivo cianoacrilato.

\section{MATERIAL E MÉTODOS}

Foram utilizados 15 eqüinos hígidos, seis machos e nove fêmeas, sem raça definida, com idade entre um ano e meio e cinco anos, pesando entre 200 e $350 \mathrm{~kg}$, divididos aleatoriamente em cinco grupos de três animais. Os animais foram previamente medicados com ivermectina ${ }^{1} \mathrm{e}$ submetidos a um período de adaptação alimentar de 15 dias.

Os eqüinos foram submetidos a medicação préanestésica com cloridrato de xilazina $^{2}$ $(1,1 \mathrm{mg} / \mathrm{kg})$. Após 10 minutos, foi aplicado éter gliceril guaiacol ${ }^{3}(110 \mathrm{mg} / \mathrm{kg})$ e, em seguida, foi feita a indução anestésica com tiopental sódico ${ }^{4}$ $(12,5 \mathrm{mg} / \mathrm{kg})$, todos por via intravenosa. Os animais foram intubados e mantidos sob anestesia pelo halotano ${ }^{5}$ vaporizado em oxigênio, em circuito semi-fechado.

A via de acesso usada foi a laparotomia paralombar esquerda, conforme Turner e McIlwraith (1982). O cólon descendente foi exteriorizado até que o ligamento duodenocólico fosse identificado. O conteúdo intestinal foi deslocado no sentido caudal e o órgão isolado com compressas estéreis. Uma enterotomia foi realizada a $40 \mathrm{~cm}$ do ligamento duodenocólico (Lucas et al., 2001) e a outra a $20 \mathrm{~cm}$ caudal à primeira. As enterotomias, de cinco centímetros cada, foram realizadas com bisturi no sentido longitudinal sobre a teniae coli, conforme Beard et al. (1989).

A sutura da primeira ferida, localizada cranialmente, foi realizada com quatro pontos de sustentação perfurantes totais distanciados um centímetro entre si, usando fio de poliglactina $910^{6} \mathrm{n}^{\circ} 0$ e fina camada de adesivo cianoacrilato ${ }^{7}$ de permeio aos pontos, para que fosse obtida a justaposição das bordas da ferida.

$\mathrm{Na}$ segunda ferida, de localização caudal, a enterorrafia foi feita em padrão interrompido perfurante total aposicional, com poliglactina $910 \mathrm{n}^{\circ} \quad 0$, mantendo espaçamento de três milímetros entre os pontos. Durante todo o procedimento cirúrgico o cólon descendente foi mantido umedecido com solução de cloreto de

\footnotetext{
${ }^{1}$ Ivomec. Merck Sharp \& Dohme AGVET. São Paulo, SP

${ }^{2}$ Rompun. Bayer. São Paulo, SP.

${ }^{3}$ Éter Gliceril Guaiacol. Henryfarma Ltda. São Paulo, SP.

${ }^{4}$ Tiopental. Cristália. Campinas, SP.

${ }^{5}$ Halotano. Cristália. Campinas, SP

${ }^{6}$ Vycril. Ethicon. São José dos Campos, SP.

${ }^{7}$ Histoacryl. B. Braun. Melsungen, Germany.
} 
sódio $^{8} 0,9 \%$ a $37^{\circ} \mathrm{C}$. Finalizadas as suturas, o cólon foi recolocado na cavidade abdominal e a laparorrafia foi feita de acordo com a técnica preconizada por Turner e Mcllwraith (1982), utilizando-se fio de náilon ${ }^{9} \mathrm{n}^{\mathrm{o}} 1$.

No período pós-cirúrgico, os pacientes receberam penicilina procaína ${ }^{10}(22.000 \mathrm{UI} / \mathrm{kg}$ a cada 12 horas) conforme McIlwraith e Turner (1987) e sulfato de gentamicina ${ }^{11}(6,6 \mathrm{mg} / \mathrm{kg}$ ao dia), de acordo com Godber et al. (1995), ambas por via intramuscular, durante cinco dias consecutivos, com exceção do grupo experimental de três dias de observação pósoperatória.

Os animais foram sacrificados aos três, sete, 14, 35 ou 70 dias de pós-operatório para observação macroscópica da cavidade abdominal e colheita de fragmentos do cólon operado para avaliação morfométrica. Para isso foram tranqüilizados com maleato de acepromazina ${ }^{12}(0,2 \mathrm{mg} / \mathrm{kg})$. Após 15 minutos administraram-se éter gliceril guaiacol $(110 \mathrm{mg} / \mathrm{kg})$ e tiopental sódico $(2 \mathrm{~g})$ e, em seguida, aplicou-se solução saturada de cloreto de potássio $(1000 \mathrm{ml})$, todos por via intravenosa.

Os fragmentos intestinais colhidos foram processados de forma rotineira para inclusão em parafina e obtenção de cortes histológicos corados pela hematoxilina-eosina e tricrômico de Masson, segundo Behmer et al. (1976).

O estudo morfométrico foi realizado em duas etapas com microscópio óptico adaptado a um sistema computadorizado de análise de imagens ${ }^{13}$. Na primeira quantificou-se o infiltrado inflamatório provocado pelas duas enterorrafias aposicionais (com poliglactina 910 e cianoacrilato). Para isso, de cada enterorrafia, foi tomado aleatoriamente um corte histológico e, neste corte, foram tomados 10 campos (área estabelecida de $23089,96 \mu \mathrm{m}^{2} /$ campo) da cicatriz para as contagens de neutrófilos, eosinófilos, macrófagos, linfócitos e plasmócitos, totalizando

\footnotetext{
${ }^{8}$ Fisiológico Cloreto de Sódio a $0,9 \%$. JP Indústria Farmacêutica S.A. Ribeirão Preto, SP.

${ }^{9}$ Mononylon. Ethicon. São José dos Campos, SP.

${ }^{10}$ Agrovet. Ciba. São Paulo, SP.

${ }^{11}$ Gentrin. Produtos Veterinários Ouro Fino Ltda. Ribeirão Preto, SP.

${ }^{12}$ Acepran $1 \%$. Univet S.A. Ind. Veterinária. São Paulo, SP.

13 Image Proplus. Cybernetics. CA, USA.
}

300 observações por variável (10 campos/enterorrafia $\mathrm{x} 2$ enterorrafias $\mathrm{x} 15$ animais).

$\mathrm{Na}$ segunda fase, em cada corte histológico, foram feitas três mensurações da espessura da incisão cirúrgica (cicatriz) e outras três da espessura de área contígua não operada (controle), estabelecendo-se as médias dos valores obtidos em cada região, perfazendo 60 observações ( 1 média/região $\times 2$ regiões $\times 2$ enterorrafias/animal x 15 animais).

O delineamento experimental foi realizado em parcelas subdivididas, sendo as parcelas constituídas pelo tempo de pós-operatório (três, sete, 14,35 e 70 dias) com três repetições (animais). Para as contagens de células inflamatórias, as subparcelas foram as enterorrafias e para os dados de espessura, foram as quatro combinações (2 enterorrafias $\mathrm{x} 2$ espessuras). As médias foram comparadas pelo teste Tukey, considerando-se o nível de 5\% de probabilidade (User's..., 1999).

\section{RESULTADOS E DISCUSSÃO}

Pelo exame necroscópico foram observados dois abscessos no grupo de 35 dias de pós-operatório, sendo um na enterorrafia aposicional com poliglactina 910 e outro na sutura com cianoacrilato. A formação dos abscessos pode ter sido facilitada pela maior susceptibilidade do cólon menor a complicações pós-operatórias (Stashak, 1982; Edwards, 1997) e as possíveis causas foram a adesão imperfeita do cianoacrilato (Inou, 1962; Matsumoto et al., 1969) ou a falha do cirurgião na execução da técnica operatória (Duarte et al., 2002). Matsumoto et al. (1969) também relataram a presença de abscessos na cavidade abdominal de cães, um junto à anastomose com polipropileno e dois na enterorrafia com cianoacrilato, nos quais foram encontrados fragmentos do adesivo tecidual.

A avaliação quantitativa do infiltrado inflamatório pelas contagens de neutrófilos, eosinófilos, macrófagos, linfócitos e plasmócitos, não indicou diferença significativa $(\mathrm{P}>0,05)$ entre as enterorrafias estudadas (Tab. 1). Fato expressivo observado na análise estatística foi o alto coeficiente de variação das contagens de 
neutrófilos, o que pode ser atribuído aos abscessos encontrados no $35^{\circ}$ dia de pósoperatório, já que neutrófilos constituem o componente principal do exsudato purulento (Thomson, 1983).

Tabela 1. Valores de F e coeficientes de variação (CV) das médias de neutrófilos, eosinófilos, macrófagos, linfócitos e plasmócitos (número por $23089,96 \mu \mathrm{m}^{2}$ ) nos segmentos do cólon descendente de eqüinos submetidos a enterorrafias aposicionais com cianoacrilato ou poliglactina

\begin{tabular}{lccccc}
\hline \multirow{2}{*}{ Estatística } & \multicolumn{5}{c}{ Variável $^{(1)}$} \\
\cline { 2 - 6 } & Neutrófilos & Eosinófilos & Macrófagos & Linfócitos & Plasmócitos \\
\hline F para dias (D) & $2,86^{*}$ & $6,15^{* *}$ & $5,90^{* *}$ & $3,91^{*}$ & 0 \\
F para enterorrafia (E) & $0,18^{\mathrm{NS}}$ & $2,57^{\mathrm{NS}}$ & $1,03^{\mathrm{NS}}$ & $0,02^{\mathrm{NS}}$ & 0 \\
F para interação DXE & $0,41^{\mathrm{NS}}$ & $0,34^{\mathrm{NS}}$ & $0,05^{\mathrm{NS}}$ & $0,63^{\mathrm{NS}}$ & 0 \\
CV $(\%)$ & 76,16 & 36,59 & 25,56 & 45,09 & 0 \\
\hline
\end{tabular}

*=significativo $(\mathrm{P} \leq 0,05) ;{ }^{*}=$ significativo $(\mathrm{P} \leq 0,01) ;{ }^{\mathrm{NS}}=$ não significativo $(\mathrm{P}>0,05)$.

${ }^{(1)}$ Dados transformados em $\sqrt{\mathrm{x}+0,5}$.

Quanto aos eosinófilos, observou-se aumento no sétimo dia de pós-operatório (Tab. 2), o que ratifica os achados de Duarte et al. (2002). A eosinofilia normalmente é descrita em infestações parasitárias e reações alérgicas (Thomson, 1983; Martin e Walker, 1991; Coelho, 2002), porém, neste estudo, assim como nos trabalhos de Faleiros et al. (2001), Lucas et al. (2001) e Lucas (2003), os animais foram medicados com ivermectina e, ainda assim, eosinófilos foram observados nas regiões intestinais estudadas. Como os eosinófilos secretam metabólitos do ácido aracdônico, potentes mediadores inflamatórios e agentes quimiotáticos (Martin e Walker, 1991), eles podem ter envolvimento com o processo inflamatório causado pelas enterotomias ou pelo material de sutura.

Tabela 2. Médias e desvios padrão obtidos na contagem de neutrófilos e eosinófilos nos segmentos do cólon descendente de eqüinos submetidos a enterorrafias aposicionais com cianoacrilato ou poliglactina nos diferentes dias de pós-operatório

\begin{tabular}{llllllll}
\hline \multirow{2}{*}{ Variável } & & \multicolumn{5}{c}{ Dias experimentais } \\
\cline { 3 - 7 } & & \multicolumn{1}{c}{$3^{\circ}$} & \multicolumn{1}{c}{$7^{\circ}$} & \multicolumn{1}{c}{$14^{\circ}$} & $35^{\circ}$ & $70^{\circ}$ & Média \\
\hline \multirow{3}{*}{ Neutrófilo } & Cianoacrilato & $3,24 \pm 0,73$ & $4,07 \pm 3,34$ & $5,24 \pm 4,84$ & $1,95 \pm 1,88)$ & 0,70 & $3,04 \pm 2,86$ \\
& Poliglactina & $5,61 \pm 0,79$ & $3,30 \pm 2,25$ & $4,63 \pm 1,45$ & $2,88 \pm 3,77$ & 0,70 & $3,43 \pm 2,47$ \\
& Média & $4,43 \pm 1,46 \mathrm{~A}$ & $3,69 \pm 2,58 \mathrm{~A}$ & $4,93 \pm 3,21 \mathrm{~A}$ & $2,42 \pm 2,71 \mathrm{~A}$ & $0,70 \mathrm{~A}$ & \\
\hline \multirow{3}{*}{ Eosinófilo } & Cianoacrilato & $0,75 \pm 0,03$ & $1,34 \pm 0,43$ & $1,39 \pm 0,64$ & $0,79 \pm 0,07$ & 0,70 & $0,99 \pm 0,43$ \\
& Poliglactina & $0,98 \pm 0,18$ & $1,88 \pm 0,71$ & $1,63 \pm 0,71$ & $0,98 \pm 0,02$ & 0,70 & $1,23 \pm 0,60$ \\
& Média & $0,87 \pm 0,17 \mathrm{BC}$ & $1,61 \pm 0,61 \mathrm{~A}$ & $1,51 \pm 0,62 \mathrm{AB}$ & $0,88 \pm 0,11 \mathrm{BC}$ & $0,70 \mathrm{C}$ \\
\hline
\end{tabular}

Médias seguidas de mesma letra não diferem entre si pelo teste Tukey $(\mathrm{P}>0,05)$.

Dados transformados em $\sqrt{\mathrm{x}+0,5}$.

Quanto aos macrófagos e linfócitos, não se observou diferença $(\mathrm{P}>0,05)$ entre as enterorrafias, porém pôde-se verificar diferenças entre os dias de pós-operatório (Tab. 1 e 3), sugerindo a persistência dos materiais de síntese no local da ferida cirúrgica. Duarte et al. (2002) relataram a presença do fio de poliglactina 910 no $35^{\circ}$ dia e resquícios dele em um animal aos 70 dias. Segundo Thomson (1983), os macrófagos persistem no sítio da lesão enquanto o antígeno estiver presente. Já os linfócitos constituem a maior população do sistema imune intestinal, responsável pelo reconhecimento dos antígenos e início da resposta imunológica, atuando sobre lesões da mucosa intestinal pela regulação de outras células, como recrutamento de neutrófilos e ativação de macrófagos (Martin e Walker, 1991). 
Aspectos morfométricos da cicatrização...

Tabela 3. Médias e desvios padrão obtidos na contagem de macrófagos e linfócitos nos segmentos do cólon descendente de eqüinos submetidos a enterorrafias aposicionais com cianoacrilato ou poliglactina nos diferentes dias de pós-operatório

\begin{tabular}{|c|c|c|c|c|c|c|c|}
\hline \multirow{2}{*}{ Variável } & & \multicolumn{6}{|c|}{ Dias experimentais } \\
\hline & & $3^{\circ}$ & $7^{\circ}$ & $14^{\circ}$ & $35^{\circ}$ & $70^{\circ}$ & Média \\
\hline \multirow{3}{*}{ Macrófago } & Cianoacrilato & $5,83 \pm 1,24$ & $6,86 \pm 0,97$ & $4,46 \pm 0,64$ & $5,49 \pm 1,55$ & $2,98 \pm 2,13$ & $5,13 \pm 1,80$ \\
\hline & Poliglactina & $6,03 \pm 0,39$ & $7,25 \pm 2,26$ & $5,15 \pm 1,35$ & $5,94 \pm 0,59$ & $3,82 \pm 1,25$ & $5,64 \pm 1,63$ \\
\hline & Média & $5,93 \pm 0,83 \mathrm{~A}$ & $7,05 \pm 1,57 \mathrm{~A}$ & $4,80 \pm 1,02 \mathrm{AB}$ & $5,71 \pm 1,08 \mathrm{AB}$ & $3,40 \pm 1,63 \mathrm{~B}$ & \\
\hline \multirow{3}{*}{ Linfócito } & Cianoacrilato & $1,81 \pm 0,67$ & $0,95 \pm 0,42$ & $1,12 \pm 0,73$ & 0,70 & $1,61 \pm 0,86$ & $1,24 \pm 0,67$ \\
\hline & Poliglactina & $2,04 \pm 0,14$ & $1,14 \pm 0,52$ & $1,22 \pm 0,89$ & 0,70 & $0,96 \pm 0,24$ & $1,21 \pm 0,61$ \\
\hline & Média & $1,93 \pm 0,45 \mathrm{~A}$ & $1,05 \pm 0,44 \mathrm{AB}$ & $1,17 \pm 0,73 \mathrm{AB}$ & $0,70 \mathrm{~B}$ & $1,28 \pm 0,66 \mathrm{AB}$ & \\
\hline
\end{tabular}

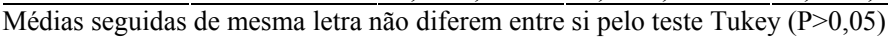

Dados transformados em $\sqrt{\mathrm{x}+0,5}$.

Os plasmócitos são células formadas pela maturação dos linfócitos $\mathrm{B}$, tendo como função a síntese e estoque de anticorpos e a sua presença nos tecidos orgânicos pode indicar que houve resposta imunológica humoral (Thomson, 1983; Coelho, 2002). São células incomuns em feridas não contaminadas em processo de cicatrização, porque há pouco material antigênico (Thomson, 1983). Neste experimento, essas células não foram encontradas nos campos histológicos examinados, sugerindo que não houve resposta imunológica humoral nos diferentes dias após a execução das enterorrafias, possivelmente, devido à baixa antigenicidade da poliglactina 910 e do cianoacrilato.

Pela mensuração das espessuras da cicatriz e das áreas contíguas não operadas, não foi encontrada diferença $(\mathrm{P}>0,05)$ entre as duas enterorrafias, tampouco nas interações entre dia e enterorrafia, dia e região, enterorrafia e região e, ainda, na interação entre dia, enterorrafia e região (Tab. 4), porém observou-se diferença $(\mathrm{P} \leq 0,05)$ entre os dias de pós-operatório (Tab. 4 e 5), o que pode ser atribuído à inflamação e reparação tecidual, com conseqüente fibrose, justificando o aumento da espessura intestinal no $14^{\circ}$ e $35^{\circ}$ dias de pósoperatório, e valores menores aos três, sete e 70 dias (Tab. 5). Ao realizarem sutura aposicional com poliglactina 910, Lucas et al. (2001) observaram fibrose intensa aos sete dias de pósoperatório e discreta ou moderada no $21^{\circ}$ e $35^{\circ}$ dias.

Independentemente da enterorrafia utilizada, também se observou diferença $(\mathrm{P} \leq 0,05)$ entre as médias da espessura das regiões da cicatriz e da área controle, cujos valores foram de 6120 e
$5169,7 \mu \mathrm{m}, \quad$ respectivamente. Isto reforça a citação de que dependendo do diâmetro do lúmen intestinal, deve-se evitar suturas invaginantes pela diminuição ainda maior deste lume (Stashak, 1982), visto que ocorre aumento da espessura da parede intestinal mesmo em suturas aposicionais em plano único.

Tabela 4. Valores de F e coeficientes de variação (CV) das médias de espessura obtidas nas regiões da incisão cirúrgica (cicatriz) e da área controle (contígua não operada) nos segmentos do cólon decendente de eqüinos submetidos a enterorrafias aposicionais com cianoacrilato ou poliglactina nos diferentes dias de pós-operatório

$\begin{array}{lc}\text { F para dias (D) } & 9,05^{*} \\ \text { F para enterorrafia (E) } & 0,03^{\mathrm{NS}} \\ \text { F para região (R) } & 5,37^{*} \\ \text { F para interação D x E } & 2,11^{\mathrm{NS}} \\ \text { F para interação D x R } & 1,23^{\mathrm{NS}} \\ \text { F para interação E x R } & 0^{\mathrm{NS}} \\ \text { F para interação D x E x R } & 1,55^{\mathrm{NS}} \\ \text { CV (\%) } & 28,12\end{array}$

$*=$ significativo $(\mathrm{P} \leq 0,05) ;{ }^{\mathrm{NS}}=$ não significativo $(\mathrm{P}>0,05)$

Nas enterorrafias aposicionais com cianoacrilato desta pesquisa não se observou a presença do fio de poliglactina 910 nos campos histológicos examinados, o que permite inferir que a reação inflamatória quantificada seja atribuída somente ao adesivo cianoacrilato aplicado na ferida intestinal. 
Tabela 5. Médias e desvios-padrão de espessuras $(\mu \mathrm{m})$ obtidas nas regiões da incisão cirúrgica (cicatriz) e da área controle (contígua não operada) nos segmentos do cólon descendente de eqüinos submetidos a enterorrafias aposicionais com cianoacrilato ou poliglactina nos diferentes dias de pós-operatório

\begin{tabular}{|c|c|c|c|c|c|c|}
\hline \multirow{2}{*}{ Enterorrafia } & \multirow{2}{*}{ Região } & \multicolumn{5}{|c|}{ Dias experimentais } \\
\hline & & $3^{\circ}$ & $7^{\circ}$ & $14^{\circ}$ & $35^{\circ}$ & $70^{\circ}$ \\
\hline & Controle & $3569,59 \pm 444,44$ & $3784,15 \pm 1193,41$ & $7373,72 \pm 1193,61$ & $7530,91 \pm 1427,58$ & $3738,54 \pm 1368,02$ \\
\hline Cianoacrilato & Cicatriz & $4800,72 \pm 1911,86$ & $4430,09 \pm 835,02$ & $8585,78 \pm 2634,45$ & $5669,86 \pm 768,25$ & $7309,08 \pm 3657,64$ \\
\hline \multirow{2}{*}{ Convencional } & Controle & $4069,51 \pm 648,63$ & $4916,48 \pm 762,40$ & $6907,04 \pm 802,90$ & $6155,64 \pm 1963,78$ & $3651,09 \pm 701,24$ \\
\hline & Cicatriz & $6535,83 \pm 1913,50$ & $5898,22 \pm 992,50$ & $7801,01 \pm 1736,64$ & $6640,90 \pm 1961,78$ & $3528,38 \pm 830,05$ \\
\hline Médias & & $4743,9 \mathrm{BC}$ & $4757,2 \mathrm{BC}$ & $7666,9 \mathrm{~A}$ & $6499,3 \mathrm{AB}$ & $4556,8 \mathrm{C}$ \\
\hline
\end{tabular}

Médias seguidas de mesma letra não diferem entre si pelo teste Tukey $(\mathrm{P}>0,05)$.

Os resultados obtidos na quantificação do infiltrado inflamatório e na mensuração da cicatriz intestinal permitem considerar a possibilidade de utilização do cianoacrilato em enterorrafias do cólon descendente de eqüinos, pois o seu uso não apresentou diferença da enterorrafia aposicional com fio de poliglactina 910. Desta forma, assim como citado por Duarte et al. (2002), em animal cuja vida pode estar comprometida pelos riscos anestésicos e cirúrgicos, em função do tempo e gravidade da lesão intestinal, o adesivo à base de cianoacrilato pode ser uma opção como material de síntese de aplicação rápida (Weilbaecher et al., 1964), em razão do processo de polimerização ocorrer entre 30 a 60 segundos (Linn et al., 1966; Duarte et al., 2002), diminuindo o tempo operatório e até aumentando a chance de sobrevivência.

A avaliação morfométrica quantitativa realizada foi válida, complementando os achados de Duarte et al. (2002), que empregaram somente avaliação qualitativa para comparar enterorrafias aposicionais com poliglactina 910 e com cianoacrilato no cólon descendente de eqüinos.

Conclui-se que os materiais de síntese avaliados nesta pesquisa apresentam a mesma eficácia para serem usados nas enterorrafias do cólon descendente de eqüinos.

\section{REFERÊNCIAS BIBLIOGRÁFICAS}

BEARD, W.L.; ROBERTSON, J.T.; GETZY, D.M. Enterotomy technique in the descending colon of the horse - Effect of location and suture pattern. Vet. Surg., v.18, p.135-140, 1989.

BEHMER, O.A.; TOLOSA, E.M.C.; FREITAS NETO, A.G. Manual de técnicas para histologia normal e patológica. São Paulo: Edart, 1976. 256p.

COELHO, H.E. Inflamação. In: Patologia veterinária. Barueri: Manole, 2002. p.45-54.

DUARTE, C.A.; CATTELAN, J.W.; ALESSI, A.C. et al. Enterorrafias em plano aposicional convencional e com adesivo tecidual à base de cianoacrilato no cólon descendente de eqüinos. Ciênc. Rural, v.32, p.595-601, 2002.

EDWARDS, G.B. Diseases and surgery of the small colon. Vet. Clin. N. Am.: Equine Pract., v.13, p.359-375, 1997.

FALEIROS, R.R.; ALVES, G.E.S.; SANTOS, R.L. et al. Experimental isquemia and reperfusion in equine small colon. Arq. Bras. Med. Vet. Zootec., v.53, p.341-350, 2001.

GODBER, L.M.; WALKER, R.D.; STEIN, G.E. et al. Pharmacokinetics, nephrotoxicosis, and in vitro antibacterial activity associated with single versus multiple (three times) daily gentamicin treatments in horses. Am. J. Vet. Res., v.56, p.613-618, 1995.

INOU, T. Studies on the surgical use of plastic adhesive. Am. J. Proctol., v.13, p.219-226, 1962.

LINN, B.S.; CECIL, F.; CONLY, P. et al. Intestinal anastomosis by invagination and gluing. Am. J. Surg., v.111, p.197-199, 1966. 
LUCAS, F.A.; CATTELAN, J.W.; CASTRO, M.B. et al. Estudo comparativo da cicatrização de enterorrafias em planos aposicional e invaginante no cólon descendente de eqüinos. Arq. Bras. Med. Vet. Zootec., v.53, p.577-584, 2001.

LUCAS, F.A. Estudo morfométrico do cólon descendente de eqüinos submetidos a enterorrafias aposicional e invaginante. 2003. 46f. Tese (Doutorado em Cirurgia Veterinária) Faculdade de Ciências Agrárias e Veterinárias, Universidade Estadual Paulista, Jaboticabal, SP.

MARTIN, S.R.; WALKER, W.A. Response of the colon to injury: inflammation, immunity and mucus. In: PHILIPS, S.D.; PEMBERTON, J.H.; SHORTER, R.G. The large intestine: physiology, pathophysiology and disease. New York: Raven, 1991. p.181-195.

MATSUMOTO, T.; PANI, K.C.; KOVARIC, J.J. et al. Tissue adhesive in intestinal surgery. Am. Surg., v.35, p.210-217, 1969.

McILWRAITH, C.W.; TURNER, A.S. Use of prophylactic antibiotics in equine surgery.
In:__ Equine surgery: advanced techniques. Philadelphia: Lea \& Febiger, 1987. p.12-19.

STASHAK, T.S. Technique for enterotomy, descompression and intestinal resection/anastomosis. Vet. Clin. N. Am.: Large Anim. Pract., v.4, p.147-165, 1982.

USER'S guide: Statistic. Version 8.8, 4.ed. Cary, NC: SAS Institute, 1999.

THOMSON, R.G. Inflamação e reparação. In:_ Patologia geral veterinária. Rio de Janeiro: Guanabara-Koogan, 1983. p.144-250.

TURNER, A.S.; McILWRAITH, C.W. Equine dental and gastrointestinal surgery. In:

Techniques in large animal surgery. Philadelphia: Lea \& Febiger, 1982. p.211-216.

WEILBAECHER, D.A.; MATHIEU, F.J.; COHN Jr., I. Nonsuture intestinal anastomosis. Am. J. Surg., v.107, p.353-360, 1964. 